\title{
Study of Blockchain Application in the Logistics Industry
}

\author{
Joyce Oliveira Déo da Silva1, Daiane Rodrigues dos Santos ${ }^{1,2}$ \\ ${ }^{1}$ Production Engineering Department, Universidade Veiga de Almeida, Rio de Janeiro, Brasil \\ ${ }^{2}$ Economic Sciences Department, Universidade do Estado do Rio de Janeiro, Rio de Janeiro, Brasil \\ Email: jo.deos@yahoo.com.br, daiane.santos@uerj.br
}

How to cite this paper: da Silva, J. O. D., \& dos Santos, D. R. (2022). Study of Blockchain Application in the Logistics Industry. Theoretical Economics Letters, 12, 321-342. https://doi.org/10.4236/tel.2022.122017

Received: February 9, 2022

Accepted: March 4, 2022

Published: March 7, 2022

Copyright $\odot 2022$ by author(s) and Scientific Research Publishing Inc. This work is licensed under the Creative Commons Attribution International License (CC BY 4.0).

http://creativecommons.org/licenses/by/4.0/

\begin{abstract}
In this article, a study of blockchain technology application in the logistics industry is presented. The main problems in the logistics area are delayed in delivery, loss of documentation, unknown source of products, errors, among others, which can be minimized and even avoided by implementing this technology. This blockchain technology initially emerged along with Bitcoin and stands out due to its qualities related to privacy, security, and authenticity. Thus, the objective of this work, exploratory and explanatory, was to evaluate the level of knowledge about the tool, the difficulties in the logistics sector and the advantages in supply chain management. This was done through the application of forms and a questionnaire aimed at determining the level of knowledge about blockchain of professionals in the logistics area and the adoption in the organizations where they work. This work aims to conduct a bibliographic study on the benefits of applying blockchain technology, proposing improvements in the information and contracting network in the logistics industry and a quality tracking system. A survey was conducted with a sample of 40 respondents. The results obtained revealed that only $42.5 \%$ of respondents had due knowledge concerning this technology, because it is recent in the logistics area. $87.5 \%$ agree that blockchain technology would solve some problems in the logistics area, however only $17.5 \%$ of the companies use the tool. About the training for the new digital era addressed in the survey, only $27.5 \%$ described that their companies invest in technology.
\end{abstract}

\section{Keywords}

Blockchain, Logistics, Supply Chain

\section{Introduction}

Blockchain technology emerged along with the digital currency Bitcoin and has 
stood out due to its qualities related to privacy, security, and authenticity. The use of the technology could happen in corporate environments in financial processes, and even in the exchange of contracts, a process that has been called "smart contract" (Lima, Hitomi, \& Oliveira, 2018: p. 6).

In addition to ensuring the transparency and immutability of the records distributed in the groups, blockchain, according to Calixto (2019: p. 3), "even has the ability to share and transfer digital objects, without the risk of a duplicate shipment or the existence of false copies in the transaction."

According to Carvalho (2006) in the 90's, the world of commerce suffered positive and negative impacts due to the emergence of computers, the creation of the internet, and the several possibilities of information transmission. Among the positive impacts are: The reliability of results; Integration of subsystems; Greater control over the organization and Savings for companies. However, whenever positive points happen, negative points appear. In relation to these negative aspects there are: The submission to the machine, the man was obliged to follow the rules imposed by the network system; The inflexibility, as when a task is implanted in the computer, for example, the flexibility disappears, as the human being has as his main characteristic to be flexible.

With the advent of the Internet network in the 90's, many countries were able to connect, "[...] including Argentina, Austria, Belgium, Brazil, Chile, Greece, India, Ireland, South Korea, Spain, and Switzerland. Several search engines emerged, such as ARCHIE and Gopher. Several institutions started to make content available online, such as the US National Library of Medicine and the Down Jones stock exchange. Additionally, reports of events against information security began to emerge [...]" (Macedo et al., 2018: p. 42).

What began in the 20th century will continue to expand in the coming decades. This current moment is referred as the information age or the digital age. In this new era, information drives every day a new order of relationships called supply chain management. Within a company's supply chain management, logistics is the function required to transport and geographically locate storage. In this way, logistics is a subset of activities and occurs within the broader framework of the chain. Bowersox et al. (2014: p. 4) mentions that:

"[...] The working objective of logistics remains essentially the same over decades, but the way the work is performed [...]" is constantly changing in the market, especially after the digital age. (Bowersox et al. 2014: p. 4)

According to Neeraja, Mehtab and Chandani (2014), a major challenge for logistics industries is to track a product, that is, to have an identification for recording process and transportation information.

To solve this challenge, it was necessary to bring the concepts of a technology called Blockchain that emerged through Bitcoin, with the proposal of exchange and transfer of values, eliminating the need for a central intermediary, such as banks, to ensure the reliability of the transaction (Neves, 2018 apud Calixto, 2019). 
Blockchain is a tool for transaction tracking and distributed and shared data that have the function of creating a secure global index for all transactions that occur in each market or production chain (Nakamoto, 2008 apud Silva et al., 2019: p. 3).

According to O'Sullivan (2018), this tool is a technology that allows for the formation of partnerships of more than one marketplace in different regions. Although this technology is most often associated with Bitcoin and other cryptocurrencies, it can be used to record all types of data. For the logistics industry, Blockchain technology promises to create transparency of all documents and transactions across the globe, freight scenario, ultimately increasing the efficiency, agility, and innovation of supply chains. As a result, industries can become more profitable and efficient, reducing costs and losses due to unforeseen events.

In this study, the origin, advantages, and functionality of blockchain technology will be discussed. Issues related to the theme of the research such as blockchain and the existing relation of this technology with the logistics area will be seen in Sections 4 and 5 respectively. To expand the knowledge of this technology, a form was applied, and its results are presented in Section 6.

To expand the knowledge about motivation within the antecedents to technology, the research brings an emerging technology (blockchain) used by IBM in a product developed for the logistics area destined to perishable products. With this, it is expected to generate a contribution to expand the knowledge about organizational motivators for the development of software aimed at the control of these products.

\section{Blockchain}

This paper researches the decentralized data storage expressed by blockchain technology and the feasibility of its development in sustainable logistics and supply chain management. Although the benefits of blockchain technology have been extensively researched in the financial sector, huge challenges in logistics such as: order delays, damage of goods, errors, and multiple data entry can be minimized with the introduction of blockchain technology. This article presents a broad review of current and gradual trends in the use of blockchain technology in logistics and supply chain management.

\subsection{Blockchain Origin and Definitions}

The idea of blockchain technology can be traced back to 1991, when Stuart Haber and W. Scott Stornetta published their work on cryptographically protected blockchains. In 1992, they incorporated Merkle trees into the project, allowing multiple documents to be collected in one block (Tijan et al., 2019).

In 2008 after the global crisis of distrust, according to Tapscott and Tapscott (2016), Satoshi Nakamoto published an article on an internet mailing list, about an electronic money transfer protocol between people P2P (Peer-to-Peer) with- 
out an intermediary and decentralized, that is, without the figure of the financial institution. This protocol comes to be Bitcoin, at its base is the blockchain technology, or as Tapscott and Tapscott (2016) called "Trust Protocol".

From then on, several debates were opened about trust, of a system that was financially centralized, and became decentralized covering other areas besides finance. An interesting detail is that the term blockchain is not mentioned in the Bitcoin article:

The Peer-to-Peer Electronic Cash System (P2P), published in 2008 by the person with the pseudonym Satoshi Nakamoto, explains that the historical records of movements are formed by a series of chained blocks, where each block stores the information of transactions with bitcoins cryptocurrencies and within the Bitcoin network, and in this series, each block is chained with cryptography to the previous block, that is, a chain of blocks, hence the term blockchain (Miranda \& Zuchi, 2018: p. 459).

The set of technologies popularized by the term blockchain can be defined, in a simplified way, as a distributed and encrypted electronic database capable of transmitting confidence about the evolution of its records to any users, without the need for a centralized and verifying organization (Campos, 2019 apud Aquino, 2019: p. 20). Blockchain is currently enjoying a rapid rise to prominence on corporate agendas as well as in the media. The mainstream awareness can largely be attributed to its original application as a digital currency technology, in particular bitcoin (Kückelhaus et al., 2018).

The first evolution according to Lamounier (2018), was Phase 1-Transactions in the period from 2008 to 2013. This period saw the first application of Blockchain technology introduced by Satoshi Nakamoto that formed the genesis block, from which other blocks were extracted, interconnected, resulting in one of the largest block chains carrying different information and transactions.

The second evolution according to Lamounier (2018), was Phase 2-Contracts in the period from 2013 to 2015. In this phase it was seen that cryptocurrency did not fully exploit the blockchain network, considering this Vitalik Buterin began working on what he believed would be a more malleable blockchain that could execute various functions. In 2013, according to (Lamounier, 2018) Ethereum was born as a new public blockchain, featuring additional functionality compared to Bitcoin. However, Vitalik Buterin showed the difference of these technologies by enabling a feature that allows people to register other assets, such as slogans and contracts. The new feature expanded Ethereum's functionality from being a cryptocurrency to being a platform for developing decentralized applications as well (Lamounier, 2018: p. 1).

The third evolution according to Lamounier (2018), was Stage 3-Applications in the period 2018, this stage is considered The Future. Some applications emerged in this stage, such as NEO, which was announced as the first open 
source, decentralized, blockchain platform launched in China. China currently according to Lamounier (2018) has banned cryptocurrencies, but NEO remains active when it comes to Blockchain innovations.

In that same phase, another platform named IOTA emerged. Lamounier (2018) addresses this platform as cryptocurrency is optimized for the Internet of Things (IoT) ecosystem, as it strives to provide zero transaction fees as well as unique verification processes. In 2017, a private company originating from block.one created EOS.IO, according to Lamounier (2018), this publication of a white paper detailed new blockchain protocols that would be powered by an EOS as a native cryptocurrency.

"EOS unfolds as a smart contract platform as well as a decentralized operating system. Its main goal is to encourage the deployment of decentralized applications through a decentralized autonomous corporation" (Lamounier, 2018: p. 1).

\subsection{Advantages of Blockchain Technology}

According to (Chang et al., 2018, own translation) Blockchain Technology has the following highlighted features and advantages:

- Transparency: Because a blockchain uses the concept of distributed consensus, all users can access the entire history of activities, which optimizes transparency data.

- Traceability: Access to time-stamped logs allows users to trace history information effectively and efficiently.

- Security: A distributed book greatly increases the difficulty of performing a cyber-attack, which significantly strengthens data security.

- Efficiency: Because blockchain replaces the need for a centralized database, disintermediation can be achieved. That is, it is no longer necessary to have a trusted intermediary, such as a bank, to maintain the database; therefore, transaction processing time and cost can be significantly reduced.

- Confidentiality: The decentralized book of a blockchain greatly enhances security and transparency; however, it raises other concerns about confidentiality, since all users of the network can see all activities. As a result, blockchain tries to preserve the privacy of users and their data by using pseudonymous addresses and advanced encryption to hide some aspects of their activities.

- Immutability: Once a transaction or activity is validated by a blockchain system, it can no longer be reversed or changed. In view of this, the integrity of your data can substantially reduce the cost of auditing.

All the information stored in the Blockchain is decentralized, as shown in Figure 1, meaning that it is not hosted only on one server, but is stored on several servers, protected by different cryptographic processes, making its modification impossible (Herrero, 2018). 

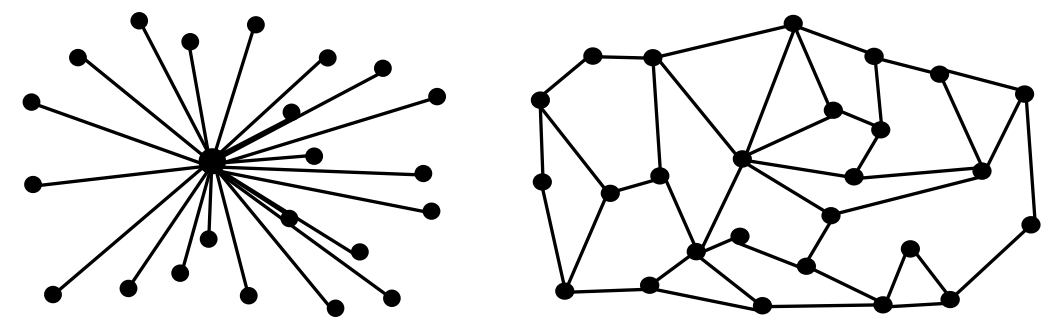

Figure 1. Centralized and decentralized network. Source: (Santos et al., 2020).

The way Blockchain works according to Ihodl (2017) is by allowing any value to be sent anywhere in the world where a Blockchain file can be accessed. It is essential that you have a private key, created cryptographically, to access only the blocks you hold. "Keys are used to access addresses that contain units of currency with financial value. Thus, the role of transfer registration, traditionally conducted by banks, is performed" (Ihodl, 2017: p. 1).

Pires (2016) complements by stating that "blockchain is a chain of immutable, public and distributed records. Considering this, it is worth noting that:

Chain because the records are carefully chained together by means of public keys, entries and exits. Immutable because once a record is entered in the chain, it can no longer be changed. Public because the only necessary condition for a citizen to have access to Blockchain records is that he has access to the internet and distributed because this record chain is not stored in a single central server, on the contrary, it is replicated in millions of machines spread around the world and no company or individual can claim ownership of these records (Pires, 2016: p. 26).

It is verified that the authors reaffirm that the concepts of chronological and immutable record in blockchain, are a data security and are in line with the principles cited by Nakamoto (2008), which are the timestamp server (that records transactions in chronological order) and the hash function (Miranda \& Zuchi, 2018).

"This hash function is considered a one-way function, meaning that it is able to encrypt the message, but it is impossible for any user to revert the encrypted message back to the original message" (Franco et al., 2018: p. 179).

The best understanding about the hash function is that it is like a "fingerprint of a block, which is used to chain it to the others" (Franco et al., 2018: p. 179). A hash function is a mathematical function that takes a variable number of characters and converts it into a series with a fixed number of characters. Even a small change in a series creates a completely new hash (Cointelegraph, 2020).

Blocks have a sequence, until reaching the first block which is called the Genesis Block. (Franco et al., 2018 apud Pires, 2016: p. 30) mention that a single second block stores hundreds of transactions that occur on the Bitcoin network. 
"When the transaction is validated, it is ready to be collected by a block and go through the mining process."

The mining process is better known as Proof-of-Work (PoW), according to Franco et al. (2018), the miner seeks to include new transactions in a block and find a mathematical solution that validates it, so it can be inserted into the existing blockchain.

\section{Supply Chain}

The supply chain is a "subset of the value chain, which is focused on adding value to a service or physical product, the supply chain is primarily concerned with the production, distribution, and sales of physical products" (Simchi-levi, Kaminsky, \& Simchi-levi, 2000 apud de Souza, Carvalho, \& Liboreiro, 2006: p. 703).

Everything we consume is a product of the supply chain. Assets around the world are extracted, designed, combined, transported, and sold every day through the supply chains that sustain global trade. Although technologies are increasingly disrupting traditional industry, this flow of goods has not been reformed in years (Tapscott \& Tapscott, 2018) apud (Becklas, 2019: p. 27).

Supply chain management "highlights the logistical interactions that occur between marketing, logistics, and production functions within a company, and of these same interactions between legally separate companies within the product flow channel" (Ballou, 2009: p. 28). The author mentions that the supply chain covers all activities related to the flow and transformation of goods from the raw material stage (extraction) to the end user, as well as the respective information flows.

There are several problems in the global logistics industry, such as a lack of transparency or a misunderstanding between agents at different layers of the supply chain. Due to this, many challenges regarding transportation protocol and product origin arise (Williams, 2015 apud Becklas, 2019: p. 28).

\section{Logistic}

Define abbreviations and acronyms the first time they are used in the text, even after they have been defined in the abstract. Abbreviations such as IEEE, SI, MKS, CGS, sc, dc, and rms do not have to be defined. Do not use abbreviations in the title or heads unless they are unavoidable.

For Ballou (2009), the definition of logistics comes to be a relatively recent management that adds value to products and services essential to consumer satisfaction.

Logistics is the activity that aims to coordinate the flow of materials, products, and services, through specialized equipment and labor, reaching its responsibility until the after-sales service, emphasizing the minimization of costs, consumer satisfaction and the achievement of competitive advantage (Dias, 1993 apud 
Brandalise, 2017).

According to Paura (2012), logistics has three basic activities, being: transportation, inventory maintenance and order processing. These three activities determine a critical factor for a logistics chain to have an adequate service.

Transportation is the basis for successful business planning. The businessman will always need to acquire raw materials and transport them to his facilities. The need to send or to pick up the goods is another point that becomes evident the correct operation of transport routes whatever it is (Paura, 2012: p. 24).

Platt (2015) believes that stock maintenance should be balanced by the number of materials and products for production and the customer, in addition to the needs of the company, without exceeding the financial limit of capital of the inventories, since this demands costs.

According to the author, order processing is the realization of the order by the users until its delivery. In this processing it is necessary to process and assemble orders faster, enabling the delivery to be on time and varied customer service.

For Alonso (2019) within the supply chain, logistics can be divided into 3 parts:

- Inbound Logistics (Supply): is part of business logistics that corresponds to the set of operations associated with the flow of materials and information for supply (or supply), from the source of raw materials to the entry into the plant.

- Internal Logistics: encompasses all material and information flows, physical moves, and operations that are performed within a company to manufacture a product.

- Outbound Logistics (Distribution): occurs after the production process, when the planning of the distribution of goods to the end customers begins. It is the entire logistical process that begins when production is complete and needs to be sold.

The logistics issue today is vital for companies as it optimizes resources and increases quality, which means spending less for better results. In logistics, tracking transactions is a major activity. Recording past actions and performance as well as planned activities is of utmost importance in this field (Dobrovnik et al., 2018, author's translation).

\section{Blockchain and Logistic}

According to Tijan et al. (2019), in the supply chain there is a complexity and lack of transparency in the processes. It is interesting for the parties involved in the logistics process to introduce and develop blockchain technology to improve the logistics processes in the supply chain, making them more sustainable.

Enterprises in the logistics and manufacturing sectors tend to implement decentralized concepts (blockchain principle) for tracking goods and transport con- 
tainers, for example. Driven by the demand for more transparency in the supply chain (traceability from start to finish) comprehensive technical solutions are a must. Blockchain or derived concepts lean toward providing solutions to numerous problems in logistics.

In addition to the hype about radical change through new sources of blockchain-based control and influence, as well as the promise of dramatically reducing the cost of transactions, blockchain technology realistically has the potential to become the record for most transactions in logistics, tracking transactions is a major activity. Recording past actions and performance as well as planned activities is of utmost importance in this field (Dobrovnik et al., 2018: p. 2, own translation).

Blockchain technology can increase the efficiency and transparency of the supply chain and positively all logistics processes, from storage to delivery and payment. In addition to the increased transparency and security achieved through blockchain, the physical flow of goods can be accelerated (Tijan et al., 2019, own translation).

In logistics, shared data across the supply chain can enable higher levels of transparency, empowering consumers to improve choices about the products they buy. These are just a few of the many opportunities that blockchain presents (Kückelhaus et al., 2018: p. 3).

Bowersox and Closs (1996) apud de Souza, Carvalho and Liboreiro (2006) point out three reasons for the need of fast information, in real time and with a high degree of accuracy for an efficient logistics and supply chain management.

First, customers understand that information on the progress of an order, product availability, delivery scheduling, and billing data are key elements of customer service. Second, with the goal of inventory reduction throughout the supply chain, executives realize that with proper information, they can effectively reduce inventory and human resource requirements. Requirement's planning being done using the latest information allows inventory to be reduced by minimizing demand uncertainty. Third, the availability of information increases flexibility with respect to knowing how much, when and where resources can be used for strategic advantage (Bowersox and Closs, 1996 apud de Souza, Carvalho, \& Liboreiro, 2006: p. 707).

The German global logistics operator Kückelhaus et al. (2018) which is an American consulting firm, produced a report on the technological potential of blockchain in logistics based on a prototype applied to the pharmaceutical industry. According to both companies, the new technology can be leveraged in asset management conferring traceability, transparency and creating value in the logistics chain. This platform can also help in the management of contracts, avoiding the need for third parties to validate them.

According to Santhi \& Muthuswamy (2022), blockchain technology provides 
all the resources needed to solve logistics inefficiencies. For this to occur blockchain needs to act as the backbone of the logistics network. It will handle everything, including providing the means to record transactions, create an efficient and transparent system, and track assets with all the necessary documentation. The decentralized structure provides the ability for all parts of the supply chain to participate and its immutable nature. Based on cryptography, it ensures security.

With "blockchain technology in the supply chain every time a product is exchanged between the sides, the transaction can be documented, creating a permanent history of a given product from manufacturing to sale" (Tijan et al., 2019: p. 7, own translation).

"During the product life cycle, as it flows through the value chain (from production to consumption), the data generated at each stage can be documented as a transaction, thus creating a permanent history of the product" (Tijan et al., 2019: p. 7, own translation).

According to Becklas (2019) Blockchain technology is useful for logistics by enabling complete supply chain visibility. Under full visibility, it is considered to show the movement of goods in various stages and processes of the supply chain and support the decision making of logistics operators.

This way of developing a business process according to Tijan et al. (2019) would fulfill the main task of logistics, which is to get goods to the right place, at the right time, in the right quantity and in the original state.

According to IDC (International Data Corporation) apud Duarte (2019) "By 2021 , annual spending is expected to reach $\$ 9.7$ billion" on Blockchain technology.

Blockchain can help all parties involved in shipping increase sustainability, reduce, or eliminate fraud and errors, improve inventory management, minimize mailing costs, reduce delays caused by paperwork, waste, and identify problems faster (Tijan et al., 2019: p. 7, own translation).

According to World Economic Forum (2013) reducing supply chain barriers could increase world GDP by almost $5 \%$ and total trade volume by $15 \%$.

\section{Relevance of Blockchain's Application to Logistics}

Since companies started manufacturing physical products, they need to arrange the movement of raw materials to their operations and finished products to their destination, as well as organize their protection, storage, and inventory control, this is called Logistics (Slack, 2015 apud Petroni, Monaco, \& Gonçalves, 2018).

This work observed the concepts of logistics within the supply chain. Over the years, the technological evolution within this area and its benefits began to be analyzed, highlighting the use of RFID technology-Radio Frequency Identification. According to Lechner et al. (2017), this technology is classified based on what is being in the process of a factory and the reader location approaches. 
Continuously with the evolution of new Blockchain-based technologies for transportation and logistics will help manage and track tens of millions of containers worldwide by digitizing the end-to-end supply chain process to increase transparency and highly secure information sharing between trading partners (IBM, 2017 apud Petroni, Monaco, \& Gonçalves, 2018: p. 70).

Badzar (2016) mentions that blockchain technology in logistics can contribute significantly to the transparency of the entire production chain, it is considered as information disclosure and is recognized as the key component to make a business sustainable. Information sharing generates and improves relationships between suppliers and customers, making transactions more efficient.

According to the recent IBM Institute Expert Insights report, "blockchain has been recognized as a technology that will be implemented in various supply chains to consider the benefits of visibility, optimization and forecasting" (Lieber, 2017 apud Becklas, 2019: p. 28).

Information regarding the shipping processes will be digital, which allows all participants to obtain the relevant data at any time. "Consequently, this reduces risks and increases the quality of delivery. In addition, it will allow organizations to decrease the amount of waste, deterioration, and defects" (Lieber, 2017 apud Becklas, 2019: p. 28).

When there is not full sharing of information, each company starts working with what it has available and ends up with wrong logical conclusions. Without this communication, production costs per unit increase, as well as higher lead times, lower product availability, and damage to the relationship between the links. The expected consequence ends up being a drop in profitability and value, and an overall drop in performance (Chopra, 2012 apud Carvalho, 2019: p. 10).

\section{Definition of the Questionnaire}

Of the studies commented on the research type, those that followed the exploratory and explanatory methodology, under the questionnaire method, were preselected. The objective was to seek a survey as a basis to develop this present study and with this, have a basis to evaluate the importance of blockchain adoption in Brazil.

The selection criteria for the questionnaire were: 1) To have people who work in logistics sectors as part of the sample; 2) To have Supply Chain Managers as part of the sample; 3) Companies in the logistics field as part of the sample, being them with anonymous identity; 4) Elaboration of a list of questions made by Google Forms.

\subsection{Form Execution}

Data collection was carried out between September 30 and November 10, 2020. The chosen collection tool was Google Forms, a free online platform for the development and execution of surveys. The connection with the respondents was 
through social networks, Linkedln, Facebook, WhatsApp, and E-mail, reaching a significant sample of 40 respondents.

The survey has an introduction where its purpose and definition about blockchain is explained, the estimated average time of completion which is 3 minutes, the confidentiality and aggregation of data at the time of publication, and the signaling that participation is voluntary, with the sole purpose of collaborating to the success of the survey.

The structure of the questionnaire for this research has nine questions and an authorization for data use, compromising the confidentiality of the respondent and his company, where it is possible to observe in Table 1 the questions, of specific and general character both organization and the informant.

Table 1. Final design of blockchain adoption survey questions.

\begin{tabular}{|c|c|c|c|}
\hline Question & Question logic & Required question & Objective \\
\hline $\begin{array}{l}\text { I declare that I agreed to participate in the field } \\
\text { research regarding Blockchain technology in the } \\
\text { logistics area. I affirm that my participation is } \\
\text { voluntary, without receiving financial incentive or } \\
\text { burden and with the sole purpose of collaborating } \\
\text { for the success of the research. I am informed that } \\
\text { the access and analysis of the data collected will be } \\
\text { carried out only by the researchers. }\end{array}$ & Multiple choice & Mandatory & $\begin{array}{l}\text { Have consent of the informant to } \\
\text { answer the other questions. }\end{array}$ \\
\hline $\begin{array}{l}\text { 1) Do you work or have worked (directly or } \\
\text { indirectly) with logistics? }\end{array}$ & Multiple choice & Mandatory & $\begin{array}{l}\text { Understand the Degree of Informant's } \\
\text { relationship with the area. }\end{array}$ \\
\hline 2) How long do you work in this area (or work)? & Multiple choice & Mandatory & $\begin{array}{l}\text { Understand the level of knowledge } \\
\text { and participation. }\end{array}$ \\
\hline $\begin{array}{l}\text { 3) What is the size of the company you work (or } \\
\text { worked) in the logistics area. }\end{array}$ & Multiple choice & Optional & Understand the size of the company. \\
\hline $\begin{array}{l}\text { 4) In your opinion, what are the biggest difficulties } \\
\text { in the logistics area? }\end{array}$ & Paragraph & Optional & $\begin{array}{l}\text { Understand the difficulties of the } \\
\text { logistics area. }\end{array}$ \\
\hline $\begin{array}{l}\text { 5) How much do you consider to know Blockchain } \\
\text { technology? }\end{array}$ & Linear scale & Mandatory & $\begin{array}{l}\text { Understand the degree of knowledge } \\
\text { of the informant about Blockchain } \\
\text { technology. }\end{array}$ \\
\hline $\begin{array}{l}\text { 6) Do you think Blockchain technology could solve } \\
\text { any problems in the logistics area? }\end{array}$ & Multiple choice & Mandatory & $\begin{array}{l}\text { Understand the visibility of the } \\
\text { Challenges of Challenges of the } \\
\text { Blockchain implementation. }\end{array}$ \\
\hline $\begin{array}{l}\text { 7) Is the company you work (or work) makes the use } \\
\text { of Blockchain technology? }\end{array}$ & Multiple choice & Mandatory & $\begin{array}{l}\text { Understanding whether all companies } \\
\text { already use technology. }\end{array}$ \\
\hline $\begin{array}{l}\text { 8) Is your company capacitating (or has already } \\
\text { enabled) employees for this digital age? }\end{array}$ & Multiple choice & Mandatory & $\begin{array}{l}\text { Understanding whether the company } \\
\text { is empowering its employees to the } \\
\text { new digital era. }\end{array}$ \\
\hline $\begin{array}{l}\text { 9) How is Blockchain technology helping your } \\
\text { company? }\end{array}$ & Paragraph & Optional & $\begin{array}{l}\text { Understand the benefits that } \\
\text { technology has brought to company. }\end{array}$ \\
\hline
\end{tabular}

Source: Elaborated by the authors, (2020). 


\subsection{Results}

In this section, the results of the Google Forms are discussed, structured in nine questions. The questionnaire captured the desired sample consisting of 40 respondents. To analyze the evidence collected, it was decided to address the eight multiple-choice questions in the questionnaire, with their respective answers, thus enabling the identification of the most relevant data.

According to the questionnaire it was possible to notice that not all respondents had knowledge about blockchain, for being a recent technology, however, plenty of knowledge in the logistics sector. However, according to the respondents, the technology could be used to improve the different bottlenecks mentioned. The details of the questions and answers can be seen in charts, tables and Graphs:

According to Graph 1, amongst the 40 respondents of the survey, $72.5 \%$ of them worked for over 4 years in the logistics area. Among the others, $5 \%$ correspond to those who have worked more than 3 years in the area, $10 \%$ have worked only 2 years, and $12.5 \%$ have worked 1 to 12 months in this logistics sector.

According to the results of question 3 shown in Graph 2, 54.1\% of respondents work in large companies with over 500 employees, $24.3 \%$ of respondents work in medium-sized companies and the remainder in small and micro-companies. Thus, it is believed that these characteristics could facilitate the application of blockchain in large companies, since they have higher revenues and the necessary tools to invest in this technology.

According to Borba, De Oliveira, \& Venanzi (2020), it is possible to affirm that blockchain has a major influence in the supply chain, which currently, is small because it is a recent technology, and little known by companies. However, it presents itself of fundamental importance, given that many large and medium sized companies need this technology to improve their management.

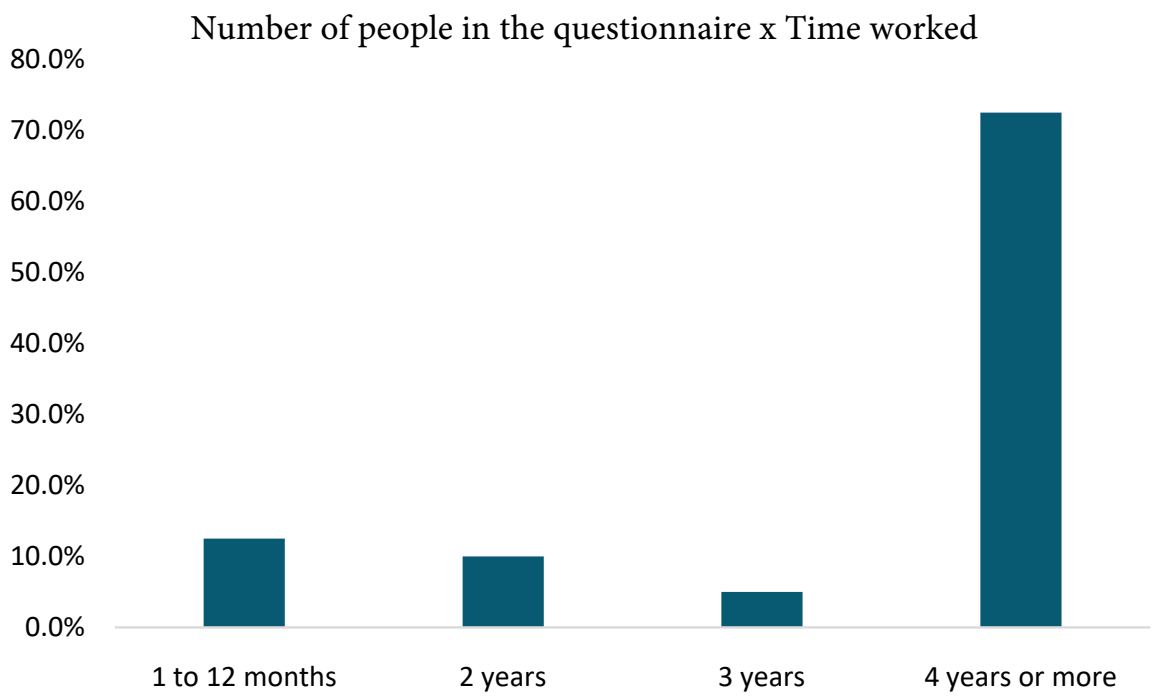

Graph 1. Working time with logistics for the agents that answered the questionnaire. Source: Elaborated by the authors. 
Size of the company that volunteers work in the logistics area
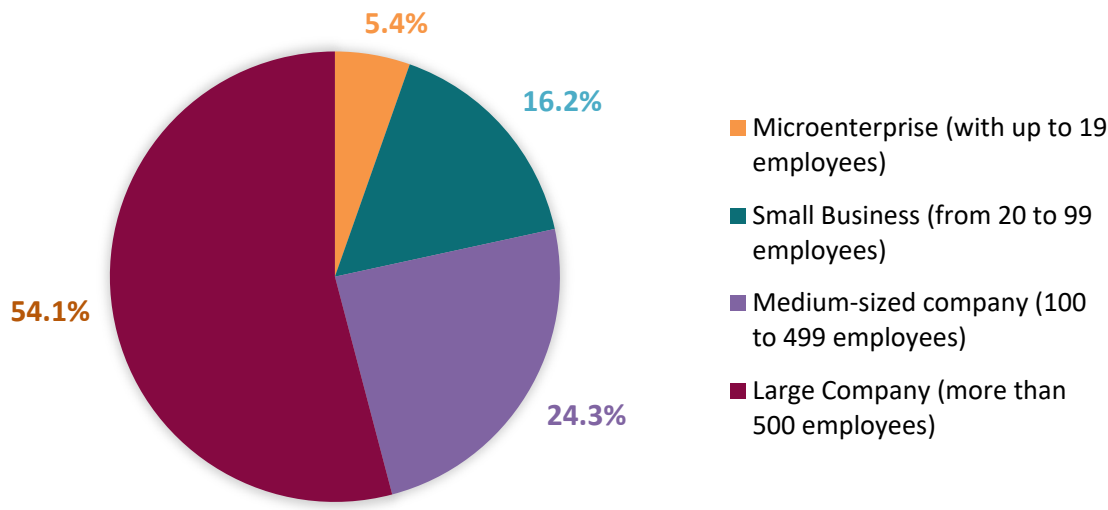

Graph 2. Information collected on the size of the company that respondents work/worked in the logistics area. Source: Elaborated by the authors.

Table 2 shows the comments of all respondents on the chosen question. The same problems such as deadline, reliability, transportation, security, costs, and others are cited in several companies. Thus, a single tool would solve these problems in all companies if applied.

Blockchain has the potential to guarantee the integrity of shared information, where all stakeholders know what happens in real time. Thinking about blockchain is thinking about the transparency of the process information, which makes the whole cycle more reliable, reducing costs with errors due to lack of communication (Calixto, 2019: p. 5).

Graph 3 presents the level of knowledge of blockchain technology among survey participants, where level 1 tends to represent those respondents do not know the technology and level 5 that they know it well. Of the 40 respondents, only 17 people had knowledge of blockchain, around $42.5 \%$ of the total. This is a satisfactory level for being a recent technology. This shows that managers, companies, and people working in the logistics area are getting qualified for a new digital age.

Graph 4 has questions about the importance of technology, where the vast majority recognize the importance of this technology (88\%).

Graph 5 shows the percentage of companies from which the respondents work, how many use this technology, showing that $82 \%$ of the respondents work in companies that use it.

In response to the number of respondents regarding the training of their staff for the new digital era, one notices that almost half (19/40) of the companies are not preparing for this possible technological revolution. $25 \%$ of the respondents don't know if their company has a continuous training policy for this theme. Graph 6 asks about the training in this area.

According to the results of Graphs 4-6, 87.5\% of the respondents are aware that blockchain technology will bring benefits to the logistics area and that $82 \%$ 
Table 2. Opinion about the difficulties of the logistics area.

\begin{tabular}{|c|c|}
\hline \multicolumn{2}{|c|}{ Biggest difficulties in logistics addressed by the employees in the questionnaire } \\
\hline Date & $\begin{array}{l}\text { In your opinion, what are the biggest difficulties in the logistics } \\
\text { area? }\end{array}$ \\
\hline $09 / 28 / 2020$ & Finding suppliers that fit the deadlines my company imposes; \\
\hline $09 / 29 / 2020$ & Organization; \\
\hline $09 / 29 / 2020$ & Alignment of collection and delivery of material. Positive feedbacks; \\
\hline $09 / 30 / 2020$ & $\begin{array}{l}\text { Lack of security in transportation, freight with outdated values, lack of } \\
\text { qualified personnel, among others; }\end{array}$ \\
\hline $09 / 30 / 2020$ & Professional training; \\
\hline $09 / 30 / 2020$ & Time; \\
\hline $10 / 01 / 2020$ & Inventory and freight; \\
\hline $10 / 01 / 2020$ & Team training, poor road conditions, gap of freight; \\
\hline $10 / 01 / 2020$ & $\begin{array}{l}\text { Difficulty in hiring professionals because of the precariousness and } \\
\text { working conditions; }\end{array}$ \\
\hline $10 / 20 / 2020$ & Professional able to apply the tools; \\
\hline $10 / 20 / 2020$ & Integration, automation and routing; \\
\hline $10 / 20 / 2020$ & Non-integration to Industry 4.0 \\
\hline $10 / 20 / 2020$ & Deadline, reliability, safety, and equipment; \\
\hline $10 / 20 / 2020$ & None; \\
\hline $10 / 20 / 2020$ & $\begin{array}{l}\text { High operating costs, safe transportation, and outdated technology. I } \\
\text { believe these } 3 \text { are the most difficult; }\end{array}$ \\
\hline $10 / 20 / 2020$ & Non-integration of Industry 4.0 \\
\hline $10 / 21 / 2020$ & None; \\
\hline $10 / 22 / 2020$ & Qualified labor; \\
\hline $10 / 22 / 2020$ & $\begin{array}{l}\text { In a large company with global operations, efficient and directed } \\
\text { communication is a point of attention that sometimes goes unnoticed } \\
\text { and harms the process. In medium-sized companies the information } \\
\text { is managed in a more controlled way, but the bottlenecks due to lack } \\
\text { of resources (operational, production, human, installation...) affect } \\
\text { the outputs. In small companies, information management is often } \\
\text { poorly managed. In general, bureaucracy interferes in any operation; }\end{array}$ \\
\hline $10 / 22 / 2020$ & $\begin{array}{l}\text { Depending on the industry, in this case the distribution, what impacts } \\
\text { are the bottlenecks in urban centers; }\end{array}$ \\
\hline $10 / 22 / 2020$ & Capacity building of logistical data; \\
\hline $10 / 22 / 2020$ & Lead time; \\
\hline $10 / 22 / 2020$ & Education and Infrastructure; \\
\hline $10 / 22 / 2020$ & $\begin{array}{l}\text { Public Administration investments, especially in transportation } \\
\text { modals. Another point are the companies that are not focused on } \\
\text { Logistics, for example commercial representatives who think that } \\
\text { logistics is not important and only manage stock, therefore they } \\
\text { don't see an opportunity in the sector; }\end{array}$ \\
\hline
\end{tabular}




\section{Continued}

\begin{tabular}{ll}
$10 / 23 / 2020$ & Logistics costs; \\
$10 / 23 / 2020$ & None; \\
$10 / 23 / 2020$ & Integration of areas, communication and process integration; \\
$10 / 24 / 2020$ & A great lack of security in cargo transportation; \\
$10 / 25 / 2020$ & Process Management; \\
$10 / 26 / 2020$ & Lack of communication; \\
$10 / 29 / 2020$ & Lack of technology; \\
$10 / 29 / 2020$ & Stocks, transportation and deliveries; \\
$10 / 30 / 2020$ & Costs related to transportation and last mile; \\
$10 / 31 / 2020$ & Technology; \\
$11 / 03 / 2020$ & Qualified labor; \\
$11 / 03 / 2020$ & None; \\
$11 / 03 / 2020$ & $\begin{array}{l}\text { The issue of communication, which impacts the inadequate } \\
\text { understanding of needs and lack of space for proper storage; }\end{array}$ \\
$\begin{array}{ll}\text { Complying with deadlines, mastering the supply chain and adequate } \\
11 / 03 / 2020\end{array}$ & $\begin{array}{l}\text { reverse logistics; } \\
\text { It is structural, in Brazil the Roads are more precarious every day, for }\end{array}$ \\
\hline $11 / 04 / 2020$ & None. \\
\hline &
\end{tabular}

Source: Elaborated by the authors.

Degree of knowledge of Blockchain Technology

18
16
14
12
10
8
6
4
2
0

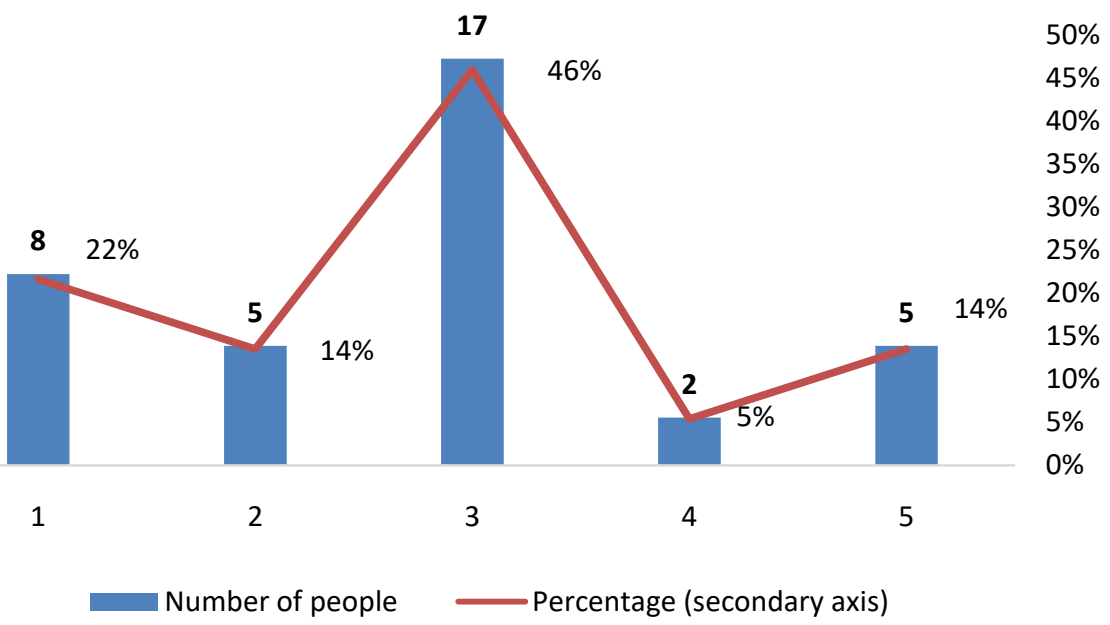

Graph 3. Knowledge of blockchain technology by the agents that answered the questionnaire. Source: Elaborated by the authors.

already use it in their companies, but that the companies where they work are not training their employees for the modernity of the internet. People who are not trained do not evolve and do not improve the processes. 
Blockchain Technology solve any problems in the logistics area?

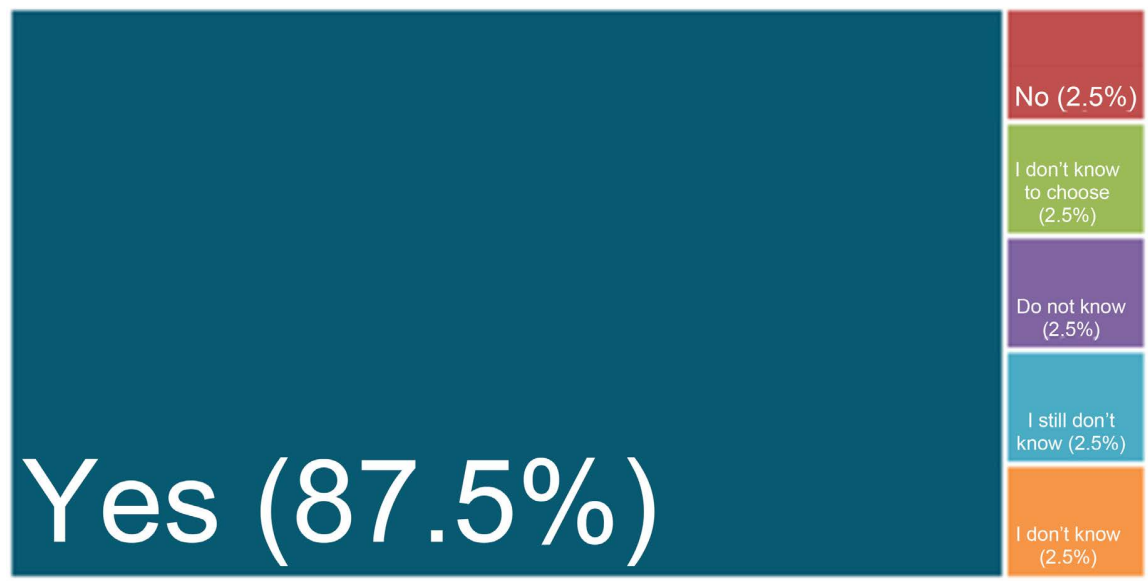

Graph 4. Opinion about the importance of blockchain technology in the logistics area. Source: Elaborated by the authors.

Does the company you work for use Blockchain Technology?

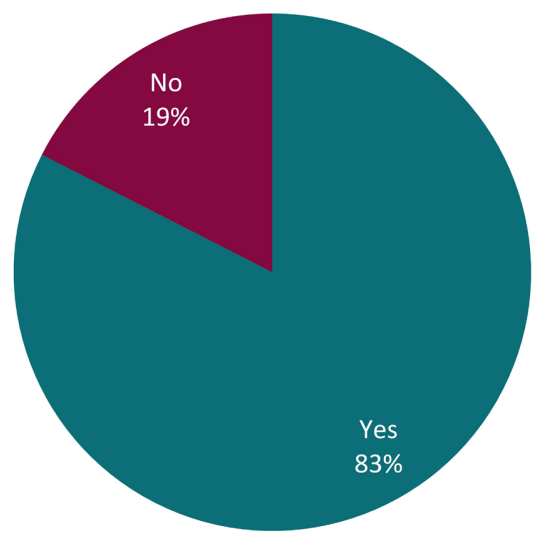

Graph 5. The number of companies where the agents work that make use of blockchain technology. Source: Elaborated by the authors.

Is your company empowering employees for this digital age?

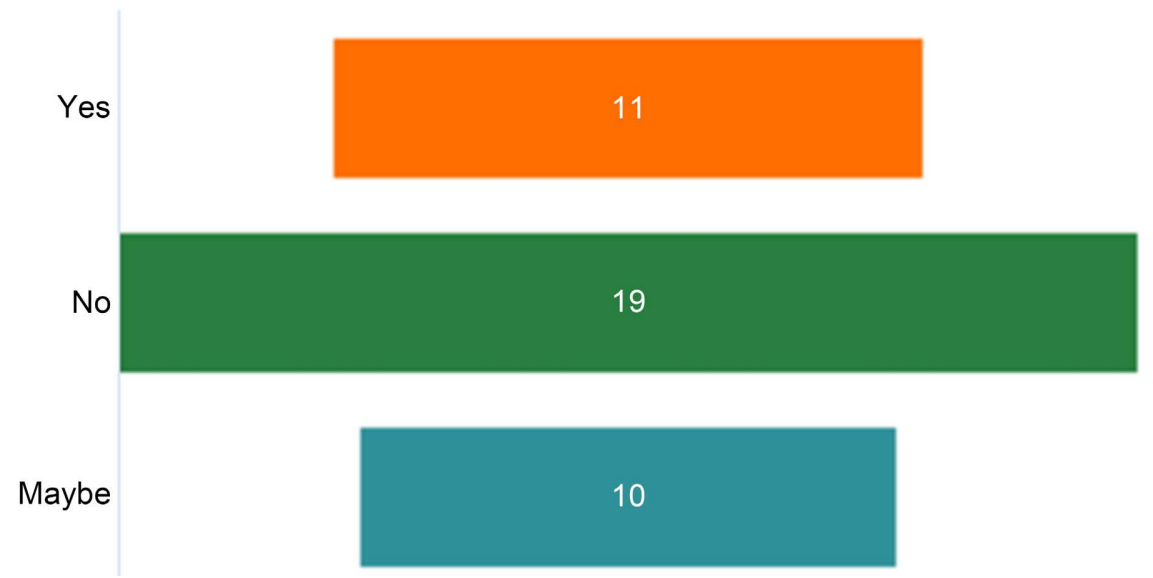

Graph 6. Quantities of agents that are being trained for the new digital era. Source: Elaborated by the authors. 
Table 3. How blockchain technology is helping in the companies that respondents work.

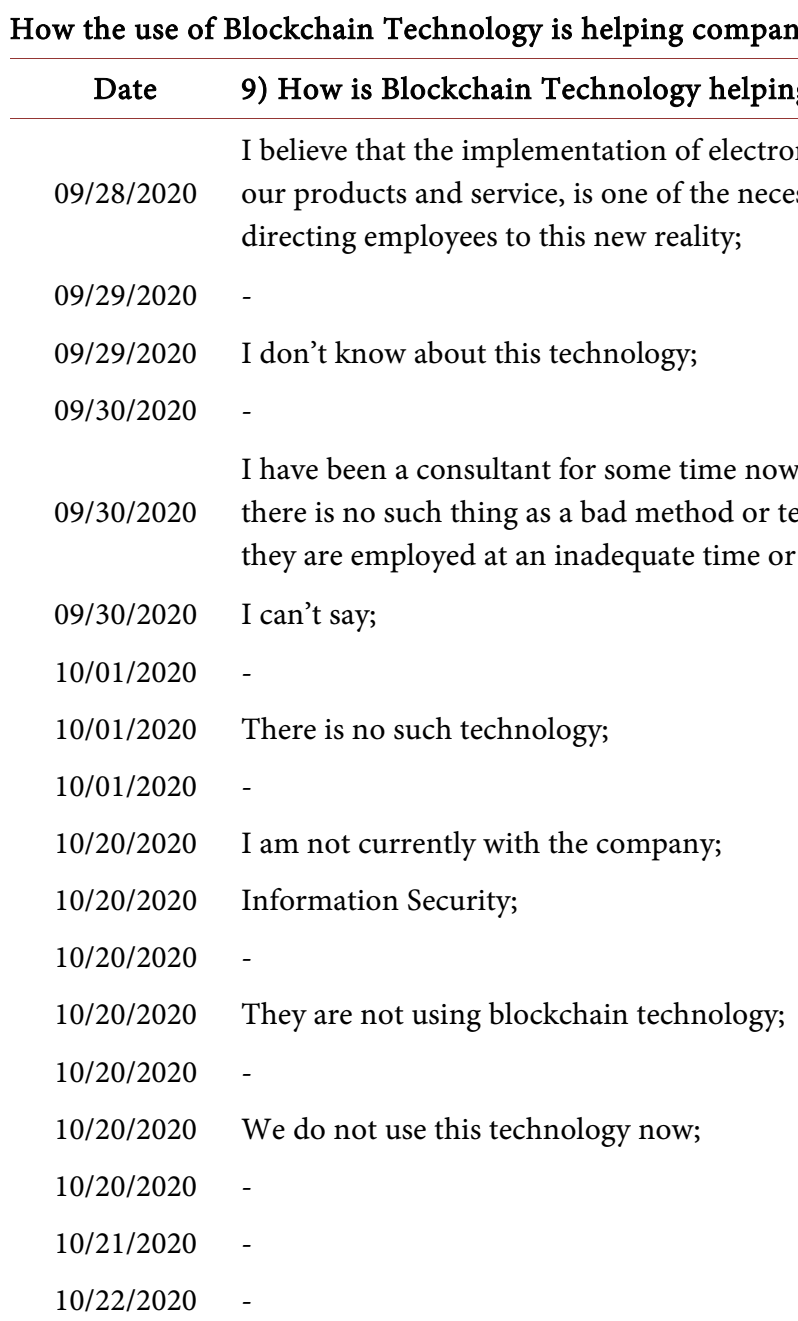

It helps in the management of information exchanged with suppliers $10 / 22 / 2020$ and customers, both internal and external, and enables timely and assertive actions to solve problems and execute activities;

$10 / 22 / 2020$ Yes

$10 / 22 / 2020$

$10 / 22 / 2020$

I don't know, maybe in Transportation;

$10 / 22 / 2020$

Traceability;

$10 / 22 / 2020$

They don't use this technology;

$10 / 23 / 2020$

We don't implement it in the company;

$10 / 23 / 2020$

$23 / 10 / 2020$

I believe that this technology will contribute to the agility in the decision making, by the companies;

$24 / 10 / 2020$

$25 / 10 / 2020$

It is not applied in my company;

$26 / 10 / 2020$

We don't know it; 


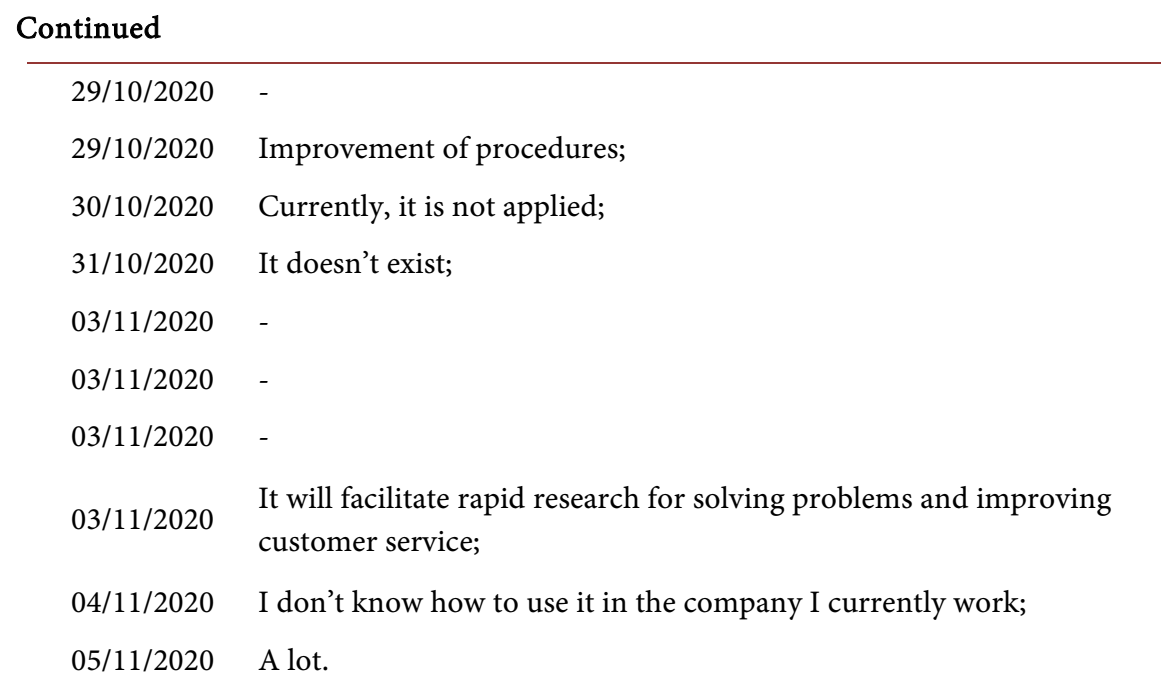

Source: Elaborated by the authors.

In Table 3 the respondents described how blockchain technology is helping to improve their companies. The main benefits were traceability, information security, direct communication of stakeholders and improvements in procedures.

For Presa (2018), one of the main benefits of blockchain is cargo tracking, where there is communication between various companies within the chain to produce the tracking data. Another positive point is the interaction of the companies involved in the chain, from the collection of the material, transportation status of the delivery, to the receipt of the cargo at its destination.

Using Blockchain, this process will be virtually all automated. "The carrier puts the signed contract in the Blockchain, the shipper confirms it, and after that, each delivery enters as a recorded information in the Blockchain and at the end of the month you just need to add up all the deliveries" (Presa, 2018: p. 1).

It should be noted that the present study was carried out without any financial and institutional support. The authors are disclosed and contacted by respondents. Due to the difficulty in contact with managers and professionals in the logistics branch and the complexity of the population, consider the sample of 40 respondents illustrative. Being able to have some bias due to the method of disclosure. There were no statistical tests and econometric analysis and rather descriptive statistics for the purpose of obtaining punctual information on the object of study. It is understood that the larger the size of the sample, the lower the likelihood that the results are biased.

\section{Conclusion}

This study describes the characteristics of blockchain, to then contextualize its importance in supply chain management in the logistics industry. The benefits and its functionalities in process improvements were exposed, based on cases disclosed in academic works and on the level of knowledge of respondents who work in the research area through the Google Form. 
Logistics is vital for organizations, consumers, and the economy. It in turn presents several challenges such as delayed deliveries, lost documentation, errors, source of documentation, and lack of training among a company's employees; these obstacles can be minimized and even avoided by implementing blockchain.

Blockchain presents several advantages such as transparency insurance, traceability, security, efficiency, reliability, and immutability; these can be good solutions to fix the supply chains regarding the logistics area, even if the application is simple, it can bring great benefits in a company's sector and in its costs.

Analyzing the results, it is possible to conclude that half of the people who answered the questionnaire work in large companies with more than 500 employees. It was possible to identify that only $42.5 \%$ of the survey participants had due knowledge about blockchain technology.

Additionally, there is a lack of usability of this technology and a lack of interest or knowledge of the companies where respondents work in relation to adoption. Although $87.5 \%$ agree that blockchain technology would solve some problems in the logistics area, only $17.5 \%$ of the companies make use of the tool. About training for the new digital era also addressed in the survey, only $27.5 \%$ described that their companies invest in technology.

Blockchain technology has gained great attention in recent years, starting in the financial sector, and is currently growing in other sectors. The amount of research seeking to understand and explore how it works is only increasing. This tool will have an impact in the coming years, generating a demand for global interest.

\section{Conflicts of Interest}

The authors declare no conflicts of interest regarding the publication of this paper.

\section{References}

Alonso, F. (2019). A abordagem Lean na cadeia de suprimentos. https://www.glean.com.br/single-post/A-abordagem-Lean-na-cadeia-de-suprimentos

Aquino, M. (2019). Adoção de blockchain na gestão de cadeias de suprimentos do brasil. Tese de Doutorado. Fundação Getúlio Vargas.

Badzar, A. (2016). Blockchain for Securing Sustainable Transport Contracts and Supply Chain Transparency. Master's Study, Lund University.

Ballou, R. (2009). Gerenciamento da Cadeia de Suprimentos/Logística Empresarial (5th ed.). Bookman Editora.

Becklas, R. (2019). Estudos dos motivadores organizacionais para o desenvolvimento de uma solução em blockchain no controle logístico de produtos perecíveis. Fundação Getúlio Vargas.

Borba, F., de Oliveira, L., \& Venanzi, D. (2020). A interferência do Blockchain na Gestão de riscos de Cadeias de Suprimentos. Refas-Revista Fatec Zona Sul, 6, 1-14.

Bowersox, D. J., Closs, D. J., Cooper, M. B., \& Bowersox, J. C. (2014). Gestão logística da 
cadeia de suprimentos (4 Edição). Artmed.

Brandalise, L. (2017). Administração de Materiais e Logística. Simplíssimo Livros Ltda.

Calixto, J. (2019). Blockchain e sua utilização nos processos logísticos (pp. 1-10). FATEC LOG.

Carvalho, M. S. R. M. (2006). A trajetória da internet no brasil: Do surgimento das redes de computadores à instituição dos mecanismos de governança. Unpublished Estudos de Ciência e Tecnologia no Brasil, Universidade Federal do Rio de Janeiro.

Carvalho, P. (2019). O impacto da blockchain nas cadeias de suprimentos (pp. 1-12). Mundo Logística.

Chang, J., Katehakis, M.N., Melamed, B., \& Shi, J. (2018). Blockchain Design for Supply Chain Management (pp. 1-36). SSRN. https://doi.org/10.2139/ssrn.3295440

Cointelegraph (2020). Como Funciona a Tecnologia Blockchain. Guia para Iniciantes. https://cointelegraph.com.br/bitcoin-for-beginners/how-blockchain-technology-works -guide-for-beginners

de Souza, G. D., de Carvalho, M. do. S. M. V., \& Liboreiro, M. A. M. (2006). Gestão da cadeia de suprimentos integrada à tecnologia da informação. Revista de Administração Pública, 40, 699-729. https://doi.org/10.1590/S0034-76122006000400010

Dobrovnik, M., Herold, D. M., Furst, E., \& Kummer, S. (2018). Blockchain for and in Logistics: What to Adopt and Where to Start. Logistics, 2, Article No. 18. https://doi.org/10.3390/logistics2030018

Duarte, L. (2019, April 17). BlockChain na Indústria 4.0: o futuro conectado de ponta a ponta, rastreabilidade e processos automatizados.

https://administradores.com.br/artigos/blockchain-na-industria-4-0-o-futuro-conectad o-de-ponta-a-ponta-rastreabilidade-e-processos-automatizados

Franco, A., Bazan, V., \& Felix, S. (2018). Criptomoedas: Melhor que dinheiro. Empiricus.

Herrero, D. (2018). Aplicación de la tecnología BlockChain en el Supply Chain en los Sectores Industriales. Universidad de Valladolid.

Ihodl (2017, June 29). Guia de blockchain para principiantes. https://pt.ihodl.com/tutorials/2017-06-29/guia-de-blockchain-para-principiantes/

Kückelhaus, M. et al. (2018). Blockchain in Logistics. DHL Customer Solutions and Innovation.

Lamounier, L. (2018, December 22). A História da Tecnologia Blockchain: Conheça sua Timeline. 101 Blockchains.

https://101blockchains.com/pt/historia-da-tecnologia-blockchain/

Lechner, J., Günthner, W. A., Nosovic, S., \& Ascher, A. (2017). Context-Based Monitoring of Logistic Process Events Using Passive UHF RFID Technology. In Proceedings of 2017 IEEE International Symposium on Robotics and Intelligent Sensors (pp. 260-265). Institute of Electrical and Electronics Engineers.

https://doi.org/10.1109/IRIS.2017.8250132

Lima, B., Hitomi, F., \& Oliveira, G. (2018). Aplicação da tecnologia blockchain em ambientes corporativos. Fasci-Tech, 1, 6-13.

Macedo, R. T., Franciscatto, R., Da Cunha, G. B., \& Bertolini, C. (2018). Redes de computadores. Universidade Federal de Santa Maria.

Miranda, J., \& Zuchi, J. (2018). Tecnologia Blockchain: A disrupção na indústria financeira. Revista Interface Tecnológica, 15, 457-469. https://doi.org/10.31510/infa.v15i2.376

Nakamoto, S. (2008). Bitcoin: A Peer-to-Peer Electronic Cash System. Bitcoin. https://bitcoin.org/bitcoin.pdf 
Neeraja, B., Mehtab, M., \& Chandani, A. (2014). Supply Chain and Logistics for the Present Day Business. Procedia Economics and Finance, 11, 665-675. https://doi.org/10.1016/S2212-5671(14)00232-9

Neves, A. (2018, May 21). Entenda Como Funcionam as Blockchains. Canaltech. https://canaltech.com.br/blockchain/entenda-como-funcionam-as-blockchains-111258/

O'Sullivan, D. (2018, August 6). West Virginia to Introduce Mobile Phone Voting for Midterm Elections. CNN Business. https://money.cnn.com/2018/08/06/technology/mobile-voting-west-virginia-voatz/ind ex.html

Paura, G. (2012). Fundamentos da Logística. Instituto Federal do Paraná.

Petroni, B. C. A., Monaco, E., \& Gonçalves, R. F. (2018). Uso de blockchain em Smart Contracts Logísticos: Uma Revisão Sistemática. South American Development Society Journal, 4, 63-81. https://doi.org/10.24325/issn.2446-5763.vespilp63-81

Pires, T. P. (2016). Tecnologia Blockchain e suas aplicações para provimento de transparência em transações eletrônicas. Universidade De Brasília.

Platt, A. (2015). Logística e Cadeia de Suprimentos (3ª ed.). Departamento de Ciências da Administração (UFSC).

Presa, C. (2018). Especialista explica como usar Blockchain na Logística. Mundo Logística, Maringá-PR.

https://revistamundologistica.com.br/entrevistas/especialista-explica-como-usar-blockc hain-na-logistica

Santhi, A. R., \& Muthuswamy, P. (2022). Influence of Blockchain Technology in Manufacturing Supply Chain and Logistics. Logistics, 6, 15.

https://doi.org/10.3390/logistics6010015

Santos, D. R., Menezes, J. F., Gentilin, V. L. S., \& Santanna, S. C. (2020). Token Economy-Uma nova maneira de investir. European Academic Research, 8, 1842-1859.

Silva, F. G. C., da Silva, F. C., de. Castro, A., \& Yano, I. H. (2019). Avaliação da técnica de blockchain na rastreabilidade na agroindústria a sucroenergética. In Encontro Nacional de Engenharia de Produção 2019. Associação Brasileira de Engenharia de Produção. https://doi.org/10.14488/ENEGEP2019 TN WIC $295666 \quad 37471$ http://edicaodobrasil.com.br/2020/07/24/setor-de-delivery-cresce-mais-de-94-durantepandemial

Tapscott, D., \& Tapscott, A. (2016). Blockchain Revolution: How the Technology behind Bitcoin Is Changing Money, Business, and the World. Penguin.

Tapscott, D., \& Tapscott, A. (2018). Blockchain Revolution: How the Technology behind Bitcoin and Other Cryptocurrencies Is Changing the World. First Portfolio.

Tijan, E., Aksentijević, S., Ivanić, K., \& Jardas, M. (2019). Blockchain Technology implEmentation in Logistics. Sustainability, 11, Article No. 1185.

https://doi.org/10.3390/su11041185

Williams, R. (2015). How Bitcoin's Technology Could Make Supply Chains More Transparent. Coindesk.

https://www.coindesk.com/how-bitcoins-technology-could-make-supply-chains-moretransparent

World Economic Forum (2013). Enabling Trade Valuing Growth Opportunities. World Economic Forum.

http://www3.weforum.org/docs/WEF SCT EnablingTrade Report 2013.pdf 